\title{
What's in a name: How do junior doctors address their consultants?
}

\author{
Authors: Alice Graham ${ }^{A}$ and Ben Messer ${ }^{B}$
}

\section{Introduction}

Evidence has suggested that when senior doctors are less approachable, junior staff are less likely to raise safety issues. There are limited existing data on whether the name by which junior doctors address their seniors reflects approachability and if this varies between grade and specialties.

\section{Methods}

An online survey was conducted in a large teaching hospital. Respondents were asked about their use of first names when addressing consultants and whether they felt this reflected their perceptions of the consultants' approachability.

Results

Four-hundred and twenty-three responses were received from a cohort of approximately 800 junior doctors. Of these, 410 were included in this analysis. Respondents came from 57 different subspecialties and all years of training. Overall, junior doctors addressed $43 \%$ of consultants by their first name; $71 \%$ of junior doctors perceived these consultants to be more approachable. There were significant differences in the results between grades and specialty of junior doctor.

\section{Conclusion}

Throughout all specialties, the majority of junior doctors consider the consultants that they address informally to be more approachable.

KEYWORDS: Medical education, junior doctors, wellbeing, training, trainee satisfaction

DOI: 10.7861/clinmed.2019-0301

\section{Introduction}

Hierarchy within medicine exists for a reason; consultants have more experience and lead the team in caring for patients. This hierarchy can, however, create an environment in which junior members of staff are afraid to 'speak up' or question seniors for fear of repercussions on training opportunities or

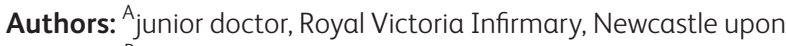
Tyne, UK; ${ }^{\text {B }}$ consultant, Royal Victoria Infirmary, Newcastle upon Tyne, UK career progression. ${ }^{1}$ One way in which this authority gradient is demonstrated is in the use of a professional title (eg Mr/Miss, Doctor, Professor) when addressing only the most senior members of the medical team. Many doctors tend to change the way they address themselves as their career progresses, moving from the use of first name to professional name. ${ }^{2}$

The aviation industry has been used as an example of transferable practice to the field of patient safety for many years. ${ }^{3}$ Tools such as checklists, training on 'non-technical' skills and significant event analysis have been integrated into modern day medical practice. ${ }^{4}$ Although a hierarchy also exists in aviation between the pilot, co-pilot and other crew it is well accepted that safety takes priority over deference. ${ }^{3}$ One way that the field of aviation has attempted to flatten this hierarchy is with the use of first names among crewmembers. As a result junior members of their team are more likely to voice concerns or ask for help. ${ }^{5}$

There is a paucity of data about which names are actually used within medicine to address colleagues, and specifically, senior staff. Furthermore, there is only limited anecdotal evidence and very little quantitative evidence. ${ }^{6,7}$ However, the idea of using first names within medicine is currently very topical, gaining press and public interest through social media movements such as '\#theatrecapchallenge. ${ }^{8}$

In this study, we sought to explore the name used by junior doctors to address consultants and whether they believe this affects their approachability.

\section{Methods}

An anonymised online survey was distributed among junior doctors working in a large tertiary NHS trust in north-east England. Individual specialty mailing lists, the medical education department and social media were all utilised to aid circulation. Responses were collected between October and November 2017.

The survey was completed voluntarily, anonymously and only by NHS staff. As such, no formal ethical approval was required. The survey contained six questions, with the first three collecting demographic information from the respondents, including specialty, grade and gender (supplementary material S1). The remaining questions explored the use of formal/informal names for consultants and opinions on approachability of consultants. Formal names were defined by the use of ' $\mathrm{Dr}$ or $\mathrm{Mr} /$ Miss or Professor' and informal by the use of first names. For the purposes of this study we used the common usage definition of 'approachable' - 'friendly and easy to talk with'. ${ }^{9}$ The term 
'consultant' is widely understood to refer to doctors who have completed specialist training.

Respondents were asked for the percentage of consultants in their own specialty whom they addressed informally. Out with their own specialty, they were asked whether they addressed the majority of consultants by informal or formal names. Finally, respondents were asked whether they found consultants that they addressed informally to be more approachable. Specialties of respondents were analysed individually and also grouped into five major categories: anaesthetics / emergency medicine, clinical sciences, medicine, paediatrics and surgery. Responses by staff other than junior doctors and incomplete questionnaires were excluded.

Data were analysed by the grade of junior doctor and their subspecialty, grouped as above. Categorical data were summarised using frequencies and percentages. Data were imported to and analysed using IBM SPSS Statistics (version 24). Statistical significance was calculated using the Chi-squared test or two-way analysis of variance (ANOVA) and defined in all cases as a p-value of $<0.05$.

\section{Results}

\section{Respondent demographics}

A total of 423 responses were received. Thirteen responses were discounted; three that were not completed by junior doctors and 10 that were incomplete. The remaining 410 responses were included for data analysis. We estimate that this demonstrates a $50 \%$ response rate among all junior doctors, including both those in formal training programmes and temporary or fellowship posts.

Replies were received from every year of training (Table 1) and 57 different specialties (supplementary material S2). Of all respondents, $48.5 \%(n=199)$ were female, $49.8 \%(n=204)$ were male and the remainder $(n=7)$ preferred not to disclose gender.

The 57 different subspecialties were grouped into five major specialties as detailed in Table 2. This allowed for easier comparison between groups.

\begin{tabular}{lll}
\hline Table 1. Grade of respondents & & \\
\hline Grade & Frequency & Percent \\
Foundation year 1 (FY1) & 34 & 8.3 \\
Foundation year 2 (FY2) & 30 & 7.3 \\
Senior house officer - non-training & 41 & 10.0 \\
grade (SHO) & & \\
Specialist registrar - non-training & 58 & 14.1 \\
grade (SPR) & & \\
Specialist trainee year 1 (ST1) & 31 & 7.6 \\
Specialist trainee year 2 (ST2) & 38 & 9.3 \\
Specialist trainee year 3 (ST3) & 36 & 8.8 \\
Specialist trainee year 4 (ST4) & 37 & 9.0 \\
Specialist trainee year 5 (ST5) & 27 & 6.6 \\
Specialist trainee year 6 (ST6) & 35 & 8.5 \\
Specialist trainee year 7 (ST7) & 25 & 6.1 \\
Specialist trainee year 8 (ST8) & 18 & 4.4 \\
Total & 410 & 100.0
\end{tabular}

Table 2. Specialty of respondents

$\begin{array}{lll}\text { Specialty } & \text { Frequency } & \text { Percent } \\ \text { Anaesthetics / emergency medicine } & 79 & 19.3 \\ \text { Clinical sciences } & 37 & 9.0 \\ \text { Medicine } & 143 & 34.9 \\ \text { Paediatrics } & 39 & 9.5 \\ \text { Surgery } & 112 & 27.3 \\ \text { Total } & 410 & 100.0\end{array}$

\section{Use of name}

On average, $42.8 \%$ (95\% confidence interval (CI) 39.1-46.1) of consultants were addressed informally by junior doctors within their own specialty. This remained consistent between gender of junior doctor (male 42.8\%; female 42.6\%; $p=0.952$ ). When addressing consultants outside the junior doctors' own specialty, $96.6 \%$ $(n=396)$ used formal names and only $3.4 \%(n=14)$ informal.

A wide variation was seen in the use of informal names between specialties. The most infrequent use of informal names to address consultants was seen in surgical specialties $(22.7 \%)$ and the most frequent in anaesthetics / emergency medicine (77.85\%; Fig 1). The largest interspecialty difference, of over $55 \%$, was observed between anaesthetics / emergency medicine and surgery $(p<0.05$; $95 \%$ CI 44.4-68.1). There was no statistically significant difference between medicine and surgery $(p=0.35 ; 95 \%$ CI $-2.8-19.4)$.

Grade of junior doctor was also shown as significant. The biggest difference was between the most junior and senior members of staff. Foundation year-1 doctors (FY1s) addressed $14.4 \%$ (range 2.2-26.7) of consultants informally, in comparison with $57.2 \%$ (range $40.4-74.1$ ) of specialty trainee year-8 doctors (ST8s; $p<0.05$; 95\% CI 6.9-78.7; Fig 2).

\section{Approachability of consultant}

The majority of junior doctors (71.0\%) reported that they found the consultants they addressed informally to be more

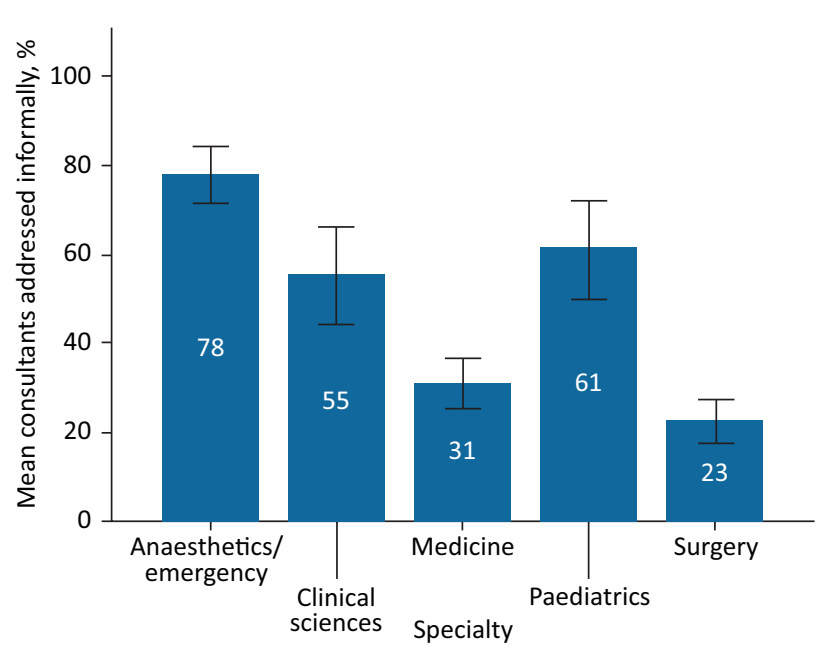

Fig 1. Mean percentage of consultants addressed informally between specialties. Error bars: $95 \%$ confidence interval. 


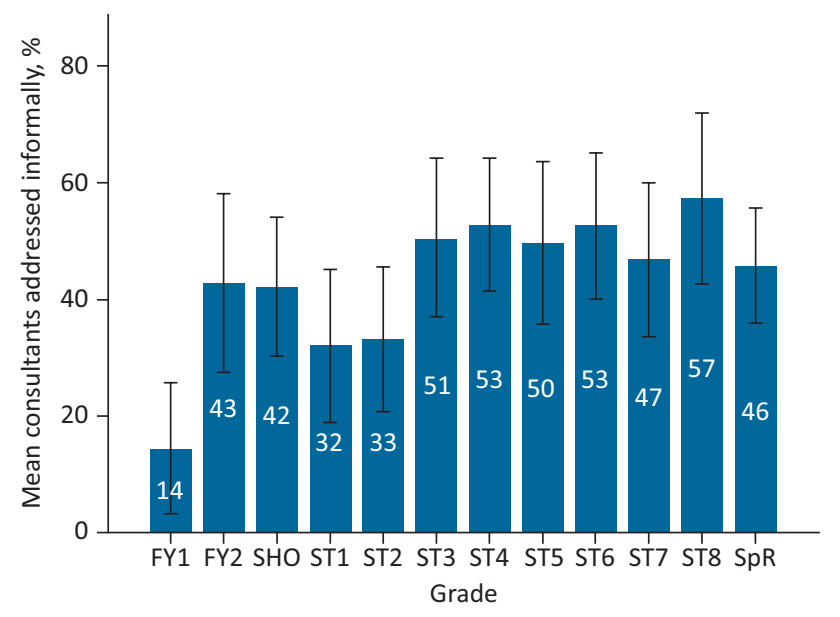

Fig 2. Mean percentage of consultants addressed informally by grade of junior doctor. Error bars: $95 \%$ confidence interval. FY1 = foundation year-1 doctor; $\mathrm{SHO}=$ senior house officer; ST1 = specialty trainee year-1 doctor; $\mathrm{SpR}=$ specialist registrar.

approachable. This was true across all specialties considered (Fig 3). This number excluded $17.6 \%(n=72)$ of the total respondents who answered this question as 'not applicable' because they did not address any consultant informally and therefore were unable to comment.

The opinion that informal names positively affect approachability of consultant was not dependent on grade of junior doctor $(p=1.64)$. While differences were observed between specialties, these were not statistically significant $(p=0.09)$.

A two-way ANOVA was used to examine whether, in specialties where informal names are used less often, their junior doctors' opinion on approachability was affected. No statistically significant interaction was identified $(p=0.20)$. This suggests that, regardless of how many consultants are addressed informally in each specialty, junior doctors universally find them more approachable.

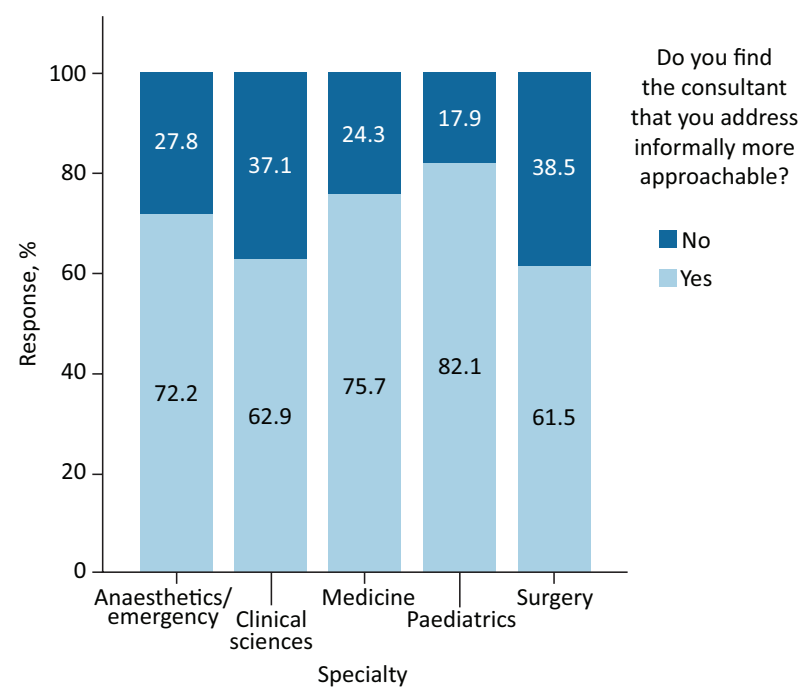

Fig 3. Effect of use of informal names on approachability of consultant by specialty.

\section{Discussion}

Our study showed that the majority of junior doctors address consultants formally and that, regardless of speciality or grade, they found these consultants to be less approachable.

Within medicine, the use of informal names as common practice is not new. In 1967, Dr Bror Rexed, the then director general of the National Swedish Board of Health and Welfare, instigated the 'Du Reforms' by proclaiming that he would address everyone on his staff by the informal pronoun ' $d u$ '. ${ }^{10}$ This use of pronouns was felt to reflect a society that didn't use nominal bias based on social class. ${ }^{11}$ Evidence looking at how this use of informal pronouns affects the doctor-patient relationship has shown that it reduces hierarchy and lessens perceived social distances.

Also accepted within modern practice of medicine is the World Health Organization (WHO) surgical safety checklist, which includes the introduction of every member of the team, but does not specify the use of first names. ${ }^{13}$ It has been suggested that when first names are used, teams work more efficiently and that this has positive implications for patient safety. ${ }^{14}$ Root cause analysis has demonstrated up to $70 \%$ of adverse events are due to communication failure. Medical and nursing teams already recognise this; in one survey, two-thirds of staff felt communication was the most important factor in improving efficiency and safety. ${ }^{16}$ In an environment such as medicine, where the stakes are so high, it is vital that we consider all potential contributions to maximising patient safety.

This is the largest study, to our knowledge, looking at the name used by junior doctors to address consultants. A similar study from 2015 that surveyed 138 foundation year doctors ${ }^{2}$ found that $11 \%$ of FY1s addressed consultants by their first name, compared with $45 \%$ of $\mathrm{FY} 2 \mathrm{~s}$. In line with our results, they also found a difference between specialties, with surgical specialties using informal names less frequently. Their findings indicated that consultants who were addressed by their first name were viewed as more approachable. This cohort of junior doctors also reported that using informal names made them feel more part of the team but, interestingly, did not impact on the likelihood that they would report a mistake to consultants. Our study showed very similar findings with regards to foundation doctors. Foundation doctors made up 15.6\% of the study cohort (8.3\% FY1 and 7.3\% FY2). Among FY1s, 14.1\% of consultants were addressed informally, compared with $42.7 \%$ in FY2s. This may reflect the specialties available to each cohort, with emergency medicine and anaesthetics generally not staffed by FY1s. Our results show that opinion regarding the relationship between approachability and use of informal names was not influenced by grade of junior doctor. This study addressed the current paucity of evidence by sampling a larger cohort than the 2015 study and, importantly, including senior trainees. We also identified that, among some specialties (anaesthetics / emergency medicine), all grades of junior doctors were more likely to use informal names.

There are a number of limitations that must be considered with this study. Firstly, the sample size within some subspecialties is very small, for example neuropsychiatry $(n=1)$ vs anaesthetics $(n=61)$. In an attempt to standardise this, these subspecialties were grouped based on common themes (anaesthetics / emergency medicine, surgery, medicine, paediatrics and clinical sciences). Dispute may exist as to which specialty some subspecialties have been categorised, for example, whether paediatric surgery is considered as under 'surgery' or 'paediatrics' or haematology as 'medicine' or 'clinical sciences'. Secondly, we divided the 
cohort of junior doctors according to gender and seniority but did not investigate the effect of country of training or other variations in training pathways. We are not aware of any validated questionnaire in this setting but recognise this would be required in any further research. We chose a simple, but easy to understand, questionnaire as an initial attempt to examine this topic.

In the future it would be important to investigate the effect that the use of informal names has on likelihood to raise concerns, staff wellbeing, specialty recruitment and trainee satisfaction. It would be challenging but interesting to examine cause and effect with respect to the use of informal names; are consultants who use first names more approachable or do more approachable consultants use their first names? While our research focuses on the names used, it does not reveal the reasons behind this choice; further work is required in collecting demographic information regarding junior doctor (country of completion of primary medical degrees), consultant (age, gender) and their relationship (length and nature). We also recognise that, although use of first names among colleagues may be preferable, in certain circumstances, such as in the presence of patients, this may not be appropriate. With the continuous drive to make the NHS more effective and efficient, the cost of introducing an initiative promoting the use of first names should be considered. This has previously been reviewed and considered to be a relatively 'low-cost' intervention when compared with other safety initiatives. ${ }^{5}$ However, critics have suggested that use of informal names may suggest a lack of respect for senior staff with resulting issues in compliance to commands and tasks.

Recently, the promotion of using first-name terms within the medical setting has gained press through the social media movement '\#theatrecapchallenge'. ${ }^{8}$ This initiative encourages all members of theatre teams to clearly display their first name and role on theatre caps. Initial results show improved rates of name recall in comparison with previous literature (30\% vs $71 \%$ ) and widespread support for the campaign ( $94 \%$ of staff supporting long-term adoption). ${ }^{17}$

Although consultants have more clinical experience and knowledge than junior members of the team, they often have similar life responsibilities. All team members are dedicated healthcare professionals and have patients' best interests at the heart of their practice. In other professional fields such as architecture, law and teaching, colleagues are commonly addressed equally. In medicine, the practice of nominal hierarchy persists. Breaking barriers created by lack of familiarity with colleagues is one potential step in encouraging stronger teamwork - for the benefit of patients and staff, whatever their grade.

\section{Supplementary material}

Additional supplementary material may be found in the online version of this article at www.rcpjournals.org/clinmedicine:

S1 - Survey.

S2 - Subspecialties of respondents.

\section{References}

1 Walton MM. Hierarchies: the Berlin Wall of patient safety. Qual Saf Heal Care 2006;15:229-30.

2 Mitchell H, Fulton A, Fertleman M, Fertleman C. Are you "Jane" or "Dr Smith"? Does formality between trainers and trainees affect training and clinical practice? BMJ 2015;351:h6427.

3 Kapur N, Parand A, Soukup T, Reader T, Sevdalis N. Aviation and healthcare: a comparative review with implications for patient safety. JRSM Open 2016;7:2054270415616548.

4 Haynes AB, Weiser TG, Berry WR et al. A surgical safety checklist to reduce morbidity and mortality in a global population. $N$ Engl J Med 2009;360:491-9.

5 Lewis GH, Vaithianathan R, Hockey PM, Hirst G, Bagian JP. Counterheroism, common knowledge, and ergonomics: concepts from aviation that could improve patient safety. Milbank Q 2011; 89:4-38.

6 Wyman AL. On first name terms. BMJ 1995;311:45

7 Ellis O. On first name terms. BMJ 2013;346:f1450.

8 Burton ZA, Guerreiro F, Turner M, Hackett R. Mad as a hatter? Evaluating doctors' recall of names in theatres and attitudes towards adopting \#theatrecapchallenge. $\mathrm{Br}$ ] Anaesth 2018;121:984-6.

9 Collins. Collins English Dictionary: Approachable. Collins, 2019. www.collinsdictionary.com/dictionary/english/approachable [Accessed 3 June 2020].

10 Royal College of Physicians. Bror Anders Rexed, Munk's Roll Volume XII. RCP. https://history.rcplondon.ac.uk/inspiring-physicians/broranders-rexed [Accessed 3 June 2020].

11 World Heritage Encyclopedia. Du-Reformen. World Heritage Encyclopedia, 2018. www.worldheritage.org/article/ WHEBN0032060526/Du-reformen [Accessed 3 June 2020].

12 Norrby C, Wide C, Lindström J, Nilsson J. Interpersonal relationships in medical consultations. Comparing Sweden Swedish and Finland Swedish address practices. J Pragmat 2015;84:121-38.

13 World Health Organization. WHO Surgical Safety Checklist 2018. WHO. www.who.int/patientsafety/topics/safe-surgery/checklist/en [Accessed 3 June 2020].

14 Bobb MR, Ahmed A, Van Heukelom P et al. Key high-efficiency practices of emergency department providers: A mixed-methods study. Acad Emerg Med 2018;25:795-803.

15 World Health Organization. Objective 9, The team will effectively communicate and exchange critical information for the safe conduct of the operation. In: WHO Guidelines for Safe Surgery 2009 Safe Surgery Saves Lives. WHO, 2009. www.ncbi.nlm.nih.gov/books/ NBK143239 [Accessed 3 June 2020].

16 Sexton JB, Thomas EJ, Helmreich RL. Error, stress, and teamwork in medicine and aviation: cross sectional surveys. BMJ 2000;320: 745-9.

17 Cohen G, Faulkner D. Memory for proper names: Age differences in retrieval. Br J Dev Psychol 1986;4:187-97.

Address for correspondence: Dr Alice Graham, Critical Care Department, Royal Victoria Infirmary, Queen Victoria Road, Newcastle-Upon-Tyne NE1 4LP, UK. Email: alicegraham2@gmail.com 